\title{
La justicia electoral rumbo a 2012. Entrevista con el licenciado José Alejandro Luna Ramos, magistrado presidente del Tribunal Electoral del Poder Judicial de la Federación, 2 de septiembre de 2011
}

1. ¿De qué manera impactó la reforma electoral de 2007 en las atribuciones, la organización y el funcionamiento del TEPJF?

Entre las principales implicaciones de la reforma electoral federal constitucional y legal de 2007-2008 para las atribuciones, organización y funcionamiento del Tribunal, pueden considerarse las siguientes:

A. Permanencia de las Salas Regionales del Tribunal Electoral del Poder Judicial de la Federación.

Quizá una de las mejores y más importantes aportaciones de la reforma. Desde su creación y hasta junio de 2008 las salas regionales no eran permanentes ya que sólo tenían competencia para las elecciones federales en una primera instancia, es decir que sus facultades eran muy limitadas y trabajaban escasamente 10 meses cada tres años.

Lo anterior generaba que la capacitación del personal de la Sala Regional se perdiera, pues cada tres años los magistrados debían buscar empleados, capacitarlos, darles un puesto de trabajo y, luego triste y absurdamente despedirlos, aunque hubieren demostrado ser valiosos y competentes, desaprovechando radicalmente la experiencia acumu- 
lada a lo largo de los meses de trabajo. Esto implicaba, además, que casi la totalidad de los asuntos electorales del país eran resueltos por la Sala Superior.

A partir de la reforma constitucional de 2007 y específicamente de la legal de 2008, se dotó a las salas regionales de competencias suficientes para la solución de algunos de los conflictos electorales generales ( $v$. gr. elecciones de los municipios y diputados de las entidades federativas en que tengan jurisdicciones y solución de los conflictos partidistas en esos mismos estados o el Distrito Federal, conjuntamente con las funciones actuales de primera instancia federal).

Paralelamente se dejó a la Sala Superior los conflictos de mayor envergadura ( $v$. gr. gobernadores y presidente de la República, y las actuales de segunda instancia federal), además de aquellos casos en que existiera contradicción de tesis entre las salas regionales y se le otorgó facultad de atracción.

\section{B. Desaplicación de leyes inconstitucionales}

Desde 1996 y hasta 2002 el Tribunal Electoral del Poder Judicial de la Federación desaplicó en el caso concreto y sin declaración general de inconstitucionalidad, aquellas leyes que si bien no habían sido impugnadas por vía de la acción de inconstitucionalidad, resultaban evidentemente contrarias a los preceptos normativos de nuestro más alto ordenamiento legal.

Al anularse en 2002 por el tribunal pleno de la Suprema Corte de Justicia de la Nación tal facultad al Tribunal Electoral se creó un verdadero "agujero negro" de control constitucional, ya que si una ley electoral no era impugnada por cuanto hace a su inconstitucionalidad en el momento correspondiente a la acción de inconstitucionalidad (esto es, 30 días después de su publicación), resultaba imposible su análisis constitucional ante ninguna otra instancia.

Por ello, fue un gran logro que en 2007 se modificara la Constitución a fin de que se le reconociera tanto a las salas Superior y regionales la capacidad de desaplicación al caso concreto de leyes inconstitucionales; estableciéndose además que debería notificarse a la Suprema Corte de Justicia de la Nación sobre el ejercicio de la mencionada facultad. 
C. Reconocimiento de los juicios para la protección de los derechos político electorales de los ciudadanos contra actos de los partidos políticos

Antes de la citada reforma, la jurisprudencia de la Sala Superior había abierto el llamado JDC de militantes, mismo que de inicio no fue del todo bien recibido por todas las dirigencias de los partidos políticos. Sin embargo, en su funcionamiento cotidiano se hicieron evidentes los beneficios de contar con un tribunal constitucional independiente que analizara el fondo de sus conflictos partidistas.

De allí que en la reforma de 2007 se reconociera la viabilidad y pertinencia de tales juicios, sólo que privilegiándose la vía autocompositiva interna, esto es: que resultaba necesario primero agotar la vía interna de resolución de controversias para, en su caso, intentar esta vía judicial (cuestión que, por otro lado, ya se había establecido en la jurisprudencia de la Sala Superior).

D. Clarificación de las reglas para los recuentos de votos

A partir de la elección presidencial de 2006, la apertura de incidentes de recuentos en casillas se tornó frecuente en la labor judicial del Tribunal; sin embargo, el esclarecimiento de las reglas de procedencia de los recuentos se dejó a la tarea de la jurisprudencia electoral.

Con la reforma de 2007 se superó esa circunstancia que era preciso atender para ofrecer mayor certeza a los justiciables, estableciéndose supuestos acotados para los que procede el incidente de recuento de votos.

\section{E. Escalonamiento en la designación de magistrados electorales}

Aun cuando dicha disposición no se ha puesto en práctica, son claras sus virtudes y previsibles impactos en la conformación y funcionamiento del Tribunal.

Hasta 2008 los magistrados de la Sala Superior eran electos por diez años, en tanto que los de las salas regionales lo eran por ocho (actualmente ambos lo son por nueve años). El hecho que todos fueron electos al mismo tiempo, determinaba también que todos terminaran al mismo tiempo el desempeño de sus funciones. 
Cada 10 y 8 años salían de súbito la totalidad de los magistrados con experiencia jurídico-electoral. Tal circunstancia fue reconocida implícitamente por las reformas de 2007 y 2008 que establecieron la designación escalonada de magistrados. Esto generará que los órganos judiciales electorales se vean beneficiados por la continuidad en la experiencia.

\section{2. ¿Cuáles son las principales acciones implementadas por el TEPJF para adecuarse a dicha reforma?}

Respondo refiriéndome a los cuatro aspectos aplicables de la reforma, destacados en mi respuesta anterior.

\section{A. Permanencia de las salas regionales del Tribunal Electoral del Poder Judicial de la Federación.}

La permanencia de las Salas Regionales planteó la necesidad de emprender acciones para fortalecer su área jurisdiccional. A ello ha contribuido el nuevo impulso que se ha dado a la capacitación interna del personal, tanto con capacitadores propios como con profesores expertos de instituciones de educación e investigación superior, como el Instituto de Investigaciones Jurídicas de la UNAM, el CIDE o la Facultad Latinoamericana de Ciencias Sociales, que imparten sus cursos bajo metodologías presenciales y también con sistemas de educación a distancia, haciendo uso de teleconferencias interactivas. Tan solo de 2009 al primer semestre de 2011 se han impartido 47 cursos de capacitación al personal del Tribunal.

De igual forma la incorporación del personal del Tribunal al servicio de carrera del Poder Judicial ha incentivado y dado mayor consistencia a la labor jurisdiccional de las salas regionales.

En el mismo sentido, se realizaron acciones tendientes a mejorar los procesos administrativos y las propias instalaciones de las salas regionales, que ahora están preparadas para desempeñarse como permanentes con toda diligencia.

En cada Sala Regional se crearon coordinaciones regionales que atienden las labores cotidianas de jurisprudencia y estadística, información, documentación, transparencia y comunicación social, entre 
otras, definiéndose una estructura y plantilla "tipo" y un nuevo esquema de operación colaborativo entre las seis salas del Tribunal (la Superior y las cinco Regionales).

Desde el 31 de julio de 2008 se declararon formalmente instaladas como permanentes las salas regionales y desde entonces la Sala Superior ha tomado las determinaciones referidas y aquellas que definieron un modelo de ingreso del personal jurídico y administrativo, una desconcentración de funciones administrativas y la operación de una visitaduría judicial que las auxilia en su labor, supervisando el adecuado cumplimiento de las normas que nos rigen orgánicamente.

\section{B. Desaplicación de leyes inconstitucionales}

Desde la entrada en vigor de la reforma electoral en cita y hasta esta fecha (agosto de 2011), las salas del Tribunal han procedido a inaplicar alguna norma por ser contraria a la Constitución en 19 de los 119 casos sometidos a su estudio. Dicha casi veintena de casos, incluye tres asuntos de 2009 en los cuales la Sala Superior consideró que la Sala Regional Toluca inaplicó implícitamente una disposición de la Ley del Municipio Libre del Estado de Colima, al tiempo que excluye la inaplicación que la Sala Regional Xalapa había realizado de una norma de derecho consuetudinario en el estado de Oaxaca y que fue revocada por la Sala Superior en sentencia recaída al recurso de apelación interpuesto, así como el que la Sala Regional Guadalajara había inaplicado, relativo a la Ley Estatal Electoral de Baja California, mediante sentencia que fue revocada por la Sala Superior al también resolver el respectivo recurso de reconsideración. ${ }^{1}$

De igual forma la Sala Superior ha aprobado una jurisprudencia y dos tesis relativas a esta nueva facultad de desaplicación de leyes inconstitucionales.

La jurisprudencia en mención es la 32/2009 aprobada el 19 de noviembre de 2009 y su rubro indica "RECURSO DE RECONSIDERACIÓN. PRocede Si EN LA SENTENCIA LA SALA REgIONAL INAPLICA, EXPRESA O IMPLÍCITAMENTE, UNA LEY ELECTORAL POR CONSIDERARLA INCONSTITUCIONAL", en tanto que la primera tesis es la XXXIII/2009 del 7 de octubre del mismo año con el rubro "INCONSTITUCIONALIDAD DE

1 Respectivamente: SUP-REC-2/2011 del 9 de marzo de 2011, y SUP-REC-5/2011 y acumulados, del 14 de marzo de 2011. 
Leyes Electorales. Se puede Plantear por CAdA ACTO DE APLiCACIÓN", siendo la segunda tesis invocada la XXII/2011 del 13 de julio de 2011 que ostenta el rubro "RECURSO DE RECONSIDERACIÓN. PROCEDE EN CONTRA DE SENTENCIAS DE LAS SALAS REGIONALES CUANDO INAPLIQUEN NORMAS CONSUETUDINARIAS DE CARÁCTER ELECTORAL”.

Éstas son las referencias fundamentales a la forma en cómo, en ejercicio de su labor jurisdiccional, el Tribunal ha dado cuenta de las nuevas facultades de control de constitucionalidad con las que le dotó la reforma de mérito.

\section{Reconocimiento de los juicios para la protección de los derechos político electorales de los ciudadanos contra actos de los partidos políticos}

En general, los juicios para la protección de los derechos político electorales de los ciudadanos es el medio de impugnación que más se promueve ante nuestra jurisdicción. Baste recordar que, de la reforma de 2007 a agosto de 2011, el número de estos juicios recibidos por el Tribunal asciende a 27816 casos que representan el 70\% del total de 39619 medios de impugnación interpuestos desde entonces.

El reconocimiento que la reforma hace de este medio para su ejercicio por parte de los militantes de los partidos ha supuesto una ampliación de los derechos de la ciudadanía que, como toda ampliación de derechos, es saludable para el avance de nuestra democracia electoral. Ello derivó de inmediato en un crecimiento de los propios juicios y naturalmente, de aquellos que promovieron los ciudadanos militantes, que en el periodo comprendido de la reforma y hasta la fecha registra un número de 10538 .

En 2008 se presentaron 2342 JDC promovidos por militantes y en 2011 (con poco más de medio año transcurrido) ya van 6105. El crecimiento es notable. Si en 2008 los JDC de los militantes alcanzaron el $70 \%$ de todos los JDC recibidos, para 2011 ese porcentaje ha crecido hasta el $87 \%$. No hay duda que se trata de un derecho ciudadano que cada vez más se ejerce con decisión y que también habla de la confianza que los militantes de los partidos depositan en el Tribunal Electoral.

En su trayectoria temporal destaca, como acabo de comentar, el presente año de 2011 por el número elevado de casos presentados. Pero también llama la atención que en 2009, año de elección federal y - por tanto- de definición de candidaturas partidistas, se hayan pro- 
movido sólo 1924 juicios por militantes, que significó apenas el 9\% del total de JDC que en ese año obtuvieron la cifra récord del periodo con 13819 juicios presentados ante el Tribunal.

Con relación a los partidos de procedencia de aquellos militantes que acuden a ejercer sus JDC ante el Tribunal, destaca el Partido Acción Nacional con un total de 8792 acumulados en el periodo, que constituye el $83 \%$ del total. Debe, sin embargo, anotarse que en el caso del PAN se han presentado en estos juicios casos de promociones "masivas" que consisten en que varios, incluso miles de militantes promueven exactamente el mismo juicio en contra de un único acto partidista. Tal fue el caso, por ejemplo, de militantes del PAN en Michoacán que en número superior a los tres mil, se inconformaron en 2011 en contra de la integración del padrón de militantes en aquella entidad.

En los números totales del periodo, al PAN le sigue el Partido de la Revolución Democrática con 889 y el Partido Revolucionario Institucional con 428.

En cuanto al sentido de las resoluciones que han recaído a dichos JDC de militantes en el periodo, es dable subrayar que se han encontrado fundados un total de 2876, lo que significa que aproximadamente prospera uno de cada tres juicios de este tipo.

\section{Clarificación de las reglas para los recuentos de votos}

El recuento de votos fue, sin duda, una de las innovaciones más sobresalientes de la reforma. Sin embargo, no ha tenido un impacto significativo sobre la labor jurisdiccional del Tribunal. Al menos no la tuvo en ocasión del proceso electoral federal de 2009.

En ese año, se presentaron tres juicios de inconformidad relacionados con el recuento de votos. El primero con relación a dos casillas del distrito 7 de Sonora, en los que se encontró procedente el incidente, llevando al recuento de votos en ambas casillas. El segundo se promovió en el distrito 17 de Jalisco para impugnar 193 casillas, encontrándose improcedente el incidente. El tercero y último se registró en el estado de Chiapas, en el distrito 2 y derivó en el recuento de votos en 20 de las 312 casillas impugnadas. ${ }^{2}$

2 Respectivamente: SG-JIN-3/2009 y SG-JIN-13/2009; SG-JIN-9/2009, y SX-JIN13/2009. 
3. ¿En qué medida la reforma constitucional de 2007 ha beneficiado la más eficaz resolución jurídica de las disputas electorales?

Con las nuevas atribuciones que se dotaron a las salas regionales, hoy tenemos una justicia más pronta y expedita; las cargas jurisdiccionales se distribuyen de mejor manera entre la Sala Superior y las cinco salas regionales.

De igual manera, la facultad de inaplicar normas contrarias a la Constitución, nos ha permitido garantizar a los justiciables que sus derechos políticos pueden ser resarcidos a través de nuestra jurisdicción.

Hoy en día el acceso a la justicia electoral se ha expandido a todos los actores que participan de alguna u otra forma en los procesos electorales. Por ejemplo, hoy los concesionarios y permisionarios de radio y televisión pueden quejarse ante un Tribunal que los escuche y ampare.

Debe subrayarse que aun cuando derivado de la ampliación de derechos de los justiciables y las atribuciones del Tribunal la carga jurisdiccional se ha incrementado, el Tribunal sigue resolviendo los asuntos que recibe en un promedio de 18.8 días, es decir: en poco más de dos semanas.

De la reforma de 2007-2008 a la fecha (agosto de 2011), el Tribunal ha recibido 39619 asuntos y resuelto 39252: el 99.07\%. Emitiendo sentencias que, como se sabe, se cumplen en un 100\%.

Como mencioné antes, el medio de impugnación que más se presenta a nuestra jurisdicción es el juicio para la protección de los derechos político electorales del ciudadano (JDC), con un acumulado de 27,816 recibidos en el periodo que representan el $70 \%$ del total. Este tipo de juicios, que tanto nos acercan a la ciudadanía, se resuelve en las salas regionales en un promedio de 14.3 días.

4. ¿Qué lecciones dejó al TEPJF la declaración de validez de la elección presidencial en 2006?

Como toda elección, la presidencial de 2006 dejó grandes enseñanzas. En buena medida, de ellas se desprendió la vasta reforma constitucio- 
nal y legal electoral federal de 2007-2008, que después fue replicada en las correspondientes reformas estatales.

El propio legislador introdujo aspectos que, ciertamente involucraron tanto a la labor jurisdiccional como a la propia estructura del Tribunal, como - por ejemplo-las nuevas normas aplicables a la calificación de la elección presidencial, incluyendo la posibilidad expresa de su nulidad.

La principal lección para el Tribunal consistió, precisamente, en la constatación de que el juez electoral sólo puede emitir sentencias con el marco legal vigente en el momento de impartir justicia electoral. $\mathrm{Ni}$ las presiones, ni sus impactos mediático, ni las confusiones o escasa compresión de la norma por otros actores, pueden ni deben influir en sus decisiones.

La fortaleza de un Tribunal reside en el Derecho y nada más.

5. ¿Cómo afectará a la labor jurisdiccional la decisión política de no realizar ajustes al marco legal de cara al próximo proceso electoral; todavía observa viabilidad de que dichas reformas pudieran aprobarse?

El Legislativo es un poder soberano del Estado mexicano. Nosotros no estamos para opinar ni de su labor, ni de las leyes que promulga. Nosotros estamos para cumplirlas.

Por disposición del artículo 105 constitucional, en principio, ya no sería momento (agosto de 2011) para realizar reformas al marco legal del próximo proceso electoral federal. Quizá después de las elecciones federales, los legisladores regresen sobre los temas que habían señalado como materia de reforma electoral. Si lo hacen, nosotros nos abocaremos a garantizar su debida observancia.

\section{6. ¿Cuáles son los principales retos del TEPJF de cara al próximo proceso electoral?}

El reto de todo Tribunal mexicano es el constitucional de impartir justicia pronta, expedita y efectiva. También lo es, por tanto, del Tribunal Electoral. 
Para ello, hemos decido fortalecer nuestra labor jurisdiccional y llevar a cabo un proceso de reorganización institucional que la apoye más decididamente.

Nuestro reto será recibir, turnar, estudiar y resolver rápido y bien todos los medios que se nos presenten, en un contexto donde las diversas impugnaciones han venido creciendo y que pueden seguir haciéndolo ante la aplicación de las nuevas reglas electorales, como la aplicación del procedimiento especial sancionador.

Lograr este propósito implica a su vez, muy diversos retos. Entre ellos y destacadamente, el de contribuir a la expansión de una cultura cívica que permita la expresión de dos de las piedras angulares de la democracia electoral: el ejercicio y defensa de los derechos políticos de la ciudadanía y la aceptabilidad de la derrota de quienes participan en los procesos electivos.

Para ello, el Tribunal despliega muy diversas acciones que nos permiten comunicar mejor y más claramente nuestras sentencias, ampliando la base de legitimidad de las autoridades electas mediante la garantía fundamental de la legalidad.

Entre esas acciones está la labor de capacitación permanente del Tribunal que lo mismo se dirige hacia su personal jurídico y administrativo, que a los tribunales e institutos electorales estatales, los propios partidos políticos y otros públicos, entre quienes se cuentan también a integrantes de los medios de comunicación.

\section{7. ¿Los precedentes emitidos por el TEPJF son suficientes para brindar certidumbre en aspectos vinculados con el derecho de réplica, la propaganda electoral, la gubernamental o la información electoral, no regulados legislativamente?}

La función jurisdiccional del Tribunal ha permitido establecer criterios bases para temas que se establecen en la normativa electoral sin contar con una reglamentación integral. Es aquí cuando los precedentes, ya sean tesis relevantes o jurisprudencia, toman un papel relevante en la justicia electoral. Gracias a los precedentes se puede dotar de certeza y seguridad jurídica a los justiciables, interpretando y dando sentido a alguna norma. 
Hemos sentado diversos criterios sobre competencia en propaganda gubernamental referido al artículo 134 constitucional, también sobre el derecho de réplica que hemos reconocido en anteriores sentencias emitidas por este Tribunal. Sin embargo, es importante que el legislador conozca estas lagunas de la ley para que puedan colmarse en un futuro ejercicio legislativo. En todo caso, nuestra jurisprudencia estará nuevamente y como siempre, a su disposición.

8. ¿Cómo mejorar la credibilidad, la confianza ciudadana y nulificar la percepción de parcialidad del Tribunal que permea en algunos representantes de la clase política y en ciertos sectores de la sociedad; la nueva agenda del magistrado presidente contempla medidas al respecto?

En verdad, le comento que la nueva agenda del magistrado presidente es la nueva agenda de la Sala Superior del Tribunal. Lo dije en mi discurso de aceptación del cargo y lo estoy cumpliendo: "nunca trabajaré de manera individual". Nunca lo he hecho y no pienso comenzar a hacerlo ahora, que formo parte de un órgano colegiado con tanto talento y experiencia.

No puedo responder en nombre de las "percepciones" que refiere, pero puedo decirle que la credibilidad y confianza ciudadana en el Tribunal se ha ganado y se gana resolviendo clara y adecuadamente cada caso que se le presenta, sin más consideraciones que las de la Constitución y las leyes reglamentarias.

Por eso, precisamente, en la nueva agenda del Tribunal está la prioridad de reforzar nuestra labor jurisdiccional. Ésa es nuestra principal función y allí radica nuestra principal fortaleza.

9. ¿Cuál será la relación del TEPJF con los partidos, los actores y los grupos de poder formales e informales?

Por la naturaleza de su función, el Tribunal sostiene - efectivamente- una relación constante y fluida con los partidos y actores polí- 
ticos, así como con los poderes formales del Estado. También con la ciudadanía, sus organizaciones y los medios de comunicación.

Con los partidos y actores electorales tendremos una relación institucional, de corte republicano: transparente, pública y por los cauces legales. Estamos aquí para garantizar a todos y por igual el cumplimiento cabal de la ley.

Con los ciudadanos tendremos una relación de cercanía y confianza. Seremos más claros en nuestra comunicación y buscaremos estrechar lazos con sus organizaciones. La ciudadanía debe saber que este Tribunal está integrado por servidores públicos y que nuestra razón última de ser radica en garantizar el ejercicio de sus derechos políticoelectorales.

No tenemos relación con ningún grupo de poder "informal” y siempre actuaremos de acuerdo con la ley y el Código de Ética del Poder Judicial de la Federación.

10. ¿Cuáles son los principales riesgos que se avizoran en el desarrollo del próximo proceso electoral?

El Tribunal Electoral no tiene entre sus funciones el de avizorar riesgos. En todo caso, registramos retos institucionales y ya me referí a ellos en la pregunta respectiva.

11. El clima de violencia e inseguridad en el país es un fenómeno presente y evidente. ¿Cuál es su percepción sobre el riesgo que ello comporta para los próximos comicios estatales y federales y cuáles serían las políticas institucionales a implementar en ese sentido?

La inseguridad es, en efecto, un fenómeno que preocupa hondamente a la ciudadanía mexicana y altera el ritmo de la nación. Lamentablemente, ello se registra también en torno a los procesos electorales. Ya hemos visto cómo, por ejemplo, la violencia de los grupos criminales ha llegado a segar la vida de candidatos. 
Éste es, por tanto, un tema muy importante para la nación y aun para las elecciones, pero no es competencia directa de nuestro Tribunal. En todo caso, es un problema muy complejo. Allí está, para demostrar la vastedad de la problemática, el documento "Elementos para la construcción de una política de Estado para la seguridad y la justicia en democracia" que elaboró recientemente la UNAM y que fue presentado por su señor rector en diversos foros durante la última semana. Ustedes como universitarios saben de ello más que yo.

De parte del Tribunal, existe una voluntad inquebrantable de unir los esfuerzos que nuestras facultades expresamente nos permitan, a los que despliegan todoslos órganos y poderes del Estado yen todos losámbitos de gobierno para enfrentar este penoso flagelo y ofrecer a la sociedad y a la ciudadanía un ambiente de seguridad.

Natural, definitiva y enfáticamente rechazamos cualquier forma de violencia y sumamos nuestro pesar al de los deudos de quienes han sufrido la secuela de la acción de criminales sin escrúpulos ni amor a México.

12. ¿Cómo describiría el estado del vínculo institucional con el IFE y cuáles son las eventuales "áreas de oportunidad" para mejorarlo?

El vínculo institucional con el IFE es virtuoso. Ambas instituciones garantizamos la solidez de la democracia electoral mexicana.

A veces, en la opinión pública se tiene la impresión de algún tipo de distanciamiento, originada en la función del Tribunal de revisar las resoluciones que le son impugnadas al IFE, a través del recurso de apelación. De alguna manera, lo mismo ocurre con los tribunales e institutos electorales estatales e incluso con los congresos locales, cuando revisamos sus decisiones mediante los medios de impugnación aplicables, como también en el ejercicio del control constitucional concreto del que estamos facultados.

Pero la verdad de los hechos es que son ratificadas más de la mitad de las resoluciones del IFE que se impugnan ante el Tribunal. Desde la reforma de 2007, el Tribunal ha conocido y resuelto en total de 1307 recursos de apelación en contra de actos y resoluciones del IFE. De ellos, la mayor parte (543 casos) han sido declarados infundados. Más 
aún, en 697 de los casos (que incluyen los declarados infundados) no se ha concedido razón al quejoso, lo que representa un 53\% de resoluciones en que se confirma o no se revoca la respectiva decisión del IFE.

Mi presidencia está y estará siempre comprometida con la construcción y profundización de la mejor relación posible con el IFE, en bien de ambas instituciones, la ciudadanía y la democracia electoral mexicana. Puedo anunciar con entusiasmo una nueva etapa de colaboración y respeto.

\section{3. ¿Cómo se prepara el TEPJF para enfrentar el escenario de una elección presidencial altamente competida que ponga en entredicho la validez de los comicios?}

Primero, habría que señalar que una elección altamente competida no necesariamente pone en entredicho la validez de sus comicios. Es más, la reforma dispuso diversas nuevas disposiciones (como el recuento de votos comentado antes) que permiten garantizar la validez de los comicios precisamente en elecciones altamente competidas.

Hecha esa primera breve consideración, puedo afirmar que el Tribunal Electoral del Poder Judicial de la Federación está listo para enfrentar el proceso electoral de 2012; tenemos una estructura sólida, con profesionales en la materia y con los recursos legales e institucionales necesarios para garantizar certeza en dichos comicios, aun cuando resultasen altamente competidos. La ciudadanía debe estar segura de que el máximo tribunal constitucional en materia electoral resolverá siempre apegado a derecho.

Estamos listos para garantizar que todos los actos relacionados con el proceso electoral federal de 2012 se lleven bajo los principios de legalidad y constitucionalidad.

En el Tribunal, los siete magistrados de la Sala Superior y los quince de las salas regionales, estamos conscientes de la responsabilidad que tenemos enfrente; entre otras, entregar la constancia de validez legal de la elección al próximo presidente de nuestra nación.

En el extremo, estamos listos para atender la carga jurisdiccional que se derive de una alta dinámica impugnativa a la que, por otra parte, ya hemos hecho frente con éxito. 
14. ¿Qué acciones tomará para afrontar con oportunidad impugnaciones derivadas por elecciones generales a nivel federal y 13 elecciones concurrentes en los estados, 6 de ellas en donde se elegirá gobernador?

Como digo, se está elaborando todo un plan estratégico que incluye preparar y disponer de los recursos humanos necesarios y altamente capacitados, los procedimientos institucionales y hasta la infraestructura y logística necesaria.

En los hechos y en los últimos años, hemos venido resolviendo una cantidad creciente de asuntos con nuevas reglas de competencia que nos han permitido perfeccionar la aplicación de la norma y prever posibles escenarios.

De igual manera, la modernización en el Tribunal seguirá permeando en nuestra labor diaria. Los procesos que hoy tenemos en la sustanciación de los medios de impugnación son totalmente transparentes para los justiciables, obrándose siempre conforme a derecho.

\section{Usted ha señalado que trabajará en el fortalecimiento de la función jurisdiccional del TEPJF. ¿Qué acciones implementará al respecto?}

Ya las estamos implementando. La idea es poner a la función jurisdiccional en el centro de toda la actividad institucional. En esa dirección se han comenzado a tomar decisiones que reorganizan la estructura administrativa del Tribunal. Todas las acciones que emprenda esta presidencia tendrán ese norte, junto con las prioridades de vigorizar la austeridad institucional y abrir al máximo de nuestras capacidades la transparencia de nuestra gestión.

Hemos hablado también con las y los magistrados de la salas regionales y estamos todos en la misma convicción y dirección. Entre todos estamos haciendo un diagnóstico muy preciso y riguroso. Como he dicho antes, ya estamos tomando medidas y quienes se han integrado a nuevas responsabilidades en áreas centrales de la administración del Tribunal tienen la instrucción precisa de proponer y ejecutar acciones 
que, en efecto, pongan de nuevo y en el centro a la función jurisdiccional.

Con esa base, le daremos a partir de ahora un mayor realce, procurando reafirmar o perfeccionar nuestros criterios jurídicos y dando plena seguridad a los justiciables que la ley seguirá imperando en las elecciones mexicanas.

\section{6. ¿Cuáles serán las prioridades y los cambios a impulsar durante su gestión como magistrado presidente?}

Desde mi mensaje de aceptación de la confianza de mis colegas magistrados, fijé las coordenadas que habrán de guiar el desempeño de esta nueva presidencia.

En él, resalté el trabajo colegiado de un órgano como la Sala Superior, reconocí el trabajo de las salas regionales, a quienes reiteré mi respeto a sus criterios jurídicos y autonomía, y convoqué a la formación colectiva de un programa de reorganización institucional para el que propuse tres prioridades iniciales:

1) Reforzar el aspecto jurisdiccional,

2) Vigorizar la austeridad institucional y

3) Abrir al máximo de nuestras capacidades la transparencia en beneficio de la ciudadanía.

17. Ha mencionado también que los ejes de la nueva gestión del TEPJF pasaran por la austeridad en el ejercicio de los recursos públicos, la transparencia y la rendición de cuentas. ¿En qué consistirán dichos cambios?

Bueno, como ya comenté, justo las y los magistrados de la Sala Superior, al lado de las y los magistrados de las cinco salas regionales, nos encontramos haciendo la valoración que nos permita definir el programa de reorganización institucional que también anuncié al aceptar la enorme y muy distinguida responsabilidad de presidir al Tribunal. Como se recordará, incluso desde que asumí la presidencia por ministerio de ley —antes de la elección del 10 de agosto- solicité a todas 
las áreas administrativas la presentación de informes sobre los que estamos haciendo el diagnóstico y construyendo colectivamente las propuestas. Esta es, como bien dices, una prioridad de la presidencia que me honro en ejercer.

La Sala Superior y la Comisión de Administración del Tribunal, de la que forman parte distinguidos integrantes del Consejo de la Judicatura, han hecho esfuerzos muy significativos para, por ejemplo, presentar durante los últimos años un presupuesto sin incrementos reales.

\section{Existen señalamientos de que en ocasiones el Tribunal sentencia de manera inconsistente casos análogos y que resuelve los asuntos más delicados con criterios políticos y no jurídicos. ¿Qué opinión tiene al respecto?}

Si bien respeto las diversas opiniones que pueden existir acerca de nuestro quehacer jurisdiccional, no comparto aquellas que afirman que nuestras decisiones se toman con criterios políticos.

Las decisiones que se toman de manera colegiada por los siete magistrados en la Sala Superior del Tribunal Electoral y por los quince magistrados que conforman las salas regionales, siempre han tenido como base fundamentos estrictamente de carácter jurídico y nada más. Los criterios relevantes, la jurisprudencia y los precedentes están presentes en todas las sentencias que emitimos, por lo que fundar y motivar nuestras decisiones con argumentos sólidos, claros y transparentes ha sido la característica principal de nuestra labor jurisdiccional.

Es cierto que por ejemplo, en ocasiones existen criterios contradictorios entre las salas regionales y la Sala Superior. Sin embargo, cuando es el caso, se presenta una contradicción de tesis que resuelve qué criterio prevalecerá para fijar jurisprudencia.

En todo caso, es muy importante que se observe con rigor nuestra labor jurisdiccional. Tanto como rigor analítico para observar e incluso criticar lo que se encuentre pertinente, como rigor metodológico para escudriñar la fortaleza argumentativa de cada sentencia.

No debe olvidarse que cada uno de los casos que se nos presentan, en número que llega casi a las cuatro decenas de millares desde la más 
reciente reforma electoral hasta la fecha, es diferente y debe resolverse en y por sus méritos: caso por caso, por lo que en ocasiones nuestros observadores los consideran aparentemente contradictorios, aunque — cuando se ven de cerca y a profundidad analítica- dejan de serlo.

\section{9. ¿Cuál es el mensaje que desea posicionar ante la ciudadanía,} en relación al papel que tendrá en las próximas elecciones?

Uno solo: que la ciudadanía mexicana cuenta con un Tribunal a su servicio, que vela efectivamente por que todos los actos y todas las resoluciones de las próximas elecciones se apeguen invariablemente a la Constitución y a las leyes, y que les ampara garantizando el ejercicio de sus derechos político electorales.

Un Tribunal que es muy fuerte y les ofrece seguridad y confianza, porque es un Tribunal apegado a derecho. Una institución republicana que será discreta en su actuación y austera en sus gastos; transparente y abierta al examen de la ciudadanía.

Un Tribunal con magistrados y magistradas que no se dejarán presionar y a los que no les temblará la mano para sostener la Constitución y fijar el rumbo democrático de las elecciones mexicanas.

\section{0. ¿Cómo ve al TEPJF, después de los cuatro años de su gestión?}

Lo veo como lo que será: "el mejor Tribunal Electoral que puede tener cualquier nación como instrumento al servicio de la justicia y de los mexicanos". Así lo dije en mi discurso del 10 de agosto y así lo creo.

Aun cuando sé que ello será obra colectiva de la Sala Superior y de las salas regionales, pondré — como he estado y estoy poniendo- todo mi empeño, toda mi dedicación y todo mi esfuerzo en esa dirección.

Un Tribunal constitucional y de la democracia mexicana, republicano, accesible, austero; ágil en su estructura, claro en su lenguaje, transparente en su administración, comprometido en su convicción por la cultura de la legalidad y la igualdad entre los mexicanos, concentrado en cuerpo y alma en su misión: impartir la justicia electoral que requiere la floreciente democracia mexicana. 